\title{
Mechanical Behavior of a Multisegmented Tower Anchorage Structure with an Exposed Steel Anchor Box
}

\author{
Wenru Lu $\mathbb{D}^{1,2,3}$ Min Zhao $\mathbb{D}^{3,4}$ and Lingling Jia $\mathbb{C}^{1}$ \\ ${ }^{1}$ School of Civil Engineering, Henan University of Technology, Zhengzhou 450001, China \\ ${ }^{2}$ Henan Key Laboratory of Grain and Oil Storage Facility \& Safety HAUT, Zhengzhou 450001, China \\ ${ }^{3}$ Highway School, Chang'an University, Xi'an 710064, China \\ ${ }^{4}$ School of Civil Engineering, Qingdao Technological University, Qingdao 266000, China \\ Correspondence should be addressed to Lingling Jia; jll8123@126.com
}

Received 26 February 2021; Revised 29 June 2021; Accepted 29 November 2021; Published 22 December 2021

Academic Editor: Haohui Xin

Copyright $\odot 2021$ Wenru Lu et al. This is an open access article distributed under the Creative Commons Attribution License, which permits unrestricted use, distribution, and reproduction in any medium, provided the original work is properly cited.

\begin{abstract}
A tower anchorage structure with an exposed steel anchor box is commonly used for cable-stayed bridges. Many researchers have conducted studies on this structure by considering a single segment. However, in practical engineering, the stress of multisegmented tower anchorage structure is not completely similar to that of single segment, and the forces between segments affect each other. Hence, in this study, the mechanical behavior of a multisegment anchorage structure with an exposed steel anchor box was investigated via finite element analysis. Furthermore, the load transfer path and stress distribution characteristics of the structure were investigated. The results indicate that the horizontal component of the cable force is borne by the side plate of the steel anchor box, the diaphragm, and the side wall of the concrete tower column, while the vertical component is transmitted by the steel anchor box and concrete tower column. Under the action of this cable force, the horizontal component of the cable force borne by the middle segment increases, while the components at the two end segments decrease. The vertical force is greater on the lower tower segments. The stress levels on the side plate and on the diaphragm of the steel anchor box in the middle section are high. Under the cable force load, the frame formed by the end plate and side plate of the steel anchor box expands outward. The end plate is mainly under a tensile load, and the tensile stress level on the lower section exceeds that on the upper section. A highstress area for the concrete tower is observed in the steel-concrete joint. The stud group of the anchorage structure is subjected to horizontal and vertical shear forces, and no "saddle-shaped" distribution of the stud shear is found. An optimal arrangement method for the stud group was proposed to optimize its mechanical performance.
\end{abstract}

\section{Introduction}

A tower anchorage structure with a steel anchor box was first used for the Ben-Ahin Bridge and Wandre Bridge in Belgium [1]. This type of structure has the advantages of an accurate anchor box fixed point and convenient construction, and it is now widely used for long-span cable-stayed bridges [2-4]. These structures can be classified into two types based on the position of the steel anchor box in the concrete tower wall: the built-in type and the exposed type. Both these types of structures can use an exposed anchorage structure because of its suitability for small-scale towers and adaptability to the tension of a prestressed steel bar $[5,6]$. This structure has been applied in large-span cable-stayed bridges, including the Normandy Bridge [7], Rion AntiBridge [8], and Hangzhou Bay Bridge [9]. The anchorage structure safely transfers the high cable force to the concrete tower, which is the key structure of the tower in a cablestayed bridge. There are many plates in the anchorage structure, and the structure is complex. Moreover, the cable holes are weakening factors. Thus, the stress state of the anchorage structure is not clear [10-12]. Therefore, it is crucial to analyze the stress of the anchorage structure appropriately to ensure the safety of the bridge.

Currently, model tests and finite element simulation analyses are generally conducted to examine the structure and analyze the stress characteristics, structural load transfer path, and ultimate bearing capacity of each component, 
considering a single segment. Zeng et al. [13] analyzed the mechanical performance of a tower anchorage structure with a steel anchor box under different load conditions, including the stress, deformation, and safety reserve of each component, via a 1: 2.5 scale model test. Moreover, in order to obtain more accurate data, full-scale tests have been carried out one after another. Zhang et al. [14], Li et al. [15], and Yu et al. [16] established finite element models based on full-scale model tests of the single-segment anchorage structure and analyzed the force transfer path and load distribution mode. In addition, Xiao et al. [17], Zhang et al. [18], and Wu et al. [19] have studied the parametric sensitivity analysis of the single-segment anchorage structure. In previous studies $[20,21]$, it has been observed that multiple segments of the anchorage structure are commonly under stress and that the forces between segments affect each other. Thus, a single-segment model cannot accurately replicate the actual stress state of an anchorage structure. Given the effect of temperature, Nie et al. [22] and Liu et al. [23] established a multisegmented tower anchorage structure and analyzed the mechanical mechanism. Wu [24] and Liang [25] et al. performed finite element analyses of a multisegment tower anchorage structure, although in-depth analysis of the steel-concrete joint was not performed, because of the large calculation workload and low calculation efficiency. Hence, the mechanical behavior of the multisegmented tower anchorage structure is not clear, which is hard to consider in designs systematically. As far as the authors' knowledge, the studies on the multisegmented tower anchorage structure are still limited.

In this study, the mechanical properties of a multisegment tower anchorage structure with an exposed steel anchor box for a cable-stayed bridge were examined using the ANSYS finite element software program. The transmission of the cable force between the plates and segments was analyzed, along with the load transfer path and loading resistance ratio for each component of the multisegment tower anchorage structure. The stress distribution of each member and the shear distribution of the studs were also investigated, and a design suggestion was proposed based on the analysis.

\section{Finite Element Numerical Model}

This investigation focuses on a semi-floating steel box girder cable-stayed bridge with double towers. The longest span is $448 \mathrm{~m}$, and the tower has an inverted diamond-shaped structure. There are 14 steel-concrete composite anchorage structures. The anchorage structure with an exposed steel anchor box is adopted for the tower, and each segment anchors two pairs of stay cables, as shown in Figure 1. The cable force is applied to the anchor pad and transmits to the side plate and end plate by the anchor plate and support plate. The side plate is subjected to the horizontal force of the cable force and drove the tension deformation of the diaphragm. The side plate and end plate transmit the vertical force downward. The group stud that connects to the side plate simultaneously transmitted the horizontal and vertical shear forces to the concrete tower.
A finite element model is established using ANSYS (Figure 2). The top five tower segments of the anchorage structure are subjected to a higher cable force, and they anchor both the tail cable and common cable. Thus, they are selected for the analysis to obtain more comprehensive results. The segments of the anchorage structure are numbered from bottom to top, as follows: GMX10-GMX14.

In the finite element model, the Solid65 element is used to simulate a concrete column and the Beam 188 element to simulate a stud. The Link8 element is adopted to simulate a tower wall steel bar, the Solid185 element is adopted to simulate the anchor pad, and Shell 181 is used to simulate the other steel plates of the anchor box. The name of each component of the steel anchor box is shown in Figure 1. The surface-surface contact element Conta174 and target element Targe 170 are adopted to simulate the interface of the steel anchor box end plate and concrete tower wall, considering a friction coefficient of 0.4 between the contact surfaces [26].

The materials in the model are defined using the elastoplasticity constitutive model. The C50 concrete material constitutive relationship curve is adopted from the concrete structural design code GB 50010-2019 [27]. A bilinear constitutive relationship is adopted for the Q345 steel plate, HRB335 steel bar, and M15 studs, and their stress-strain relationship curves are shown in Figure 3.

The cable force is simulated as the node load and applied to the anchor pad. The cable forces in the bridge under a dead load state for each cable segment are listed in Table 1. To reduce the influence of the boundary conditions on the calculation results, an additional segment of the concrete tower column is included underneath. In other words, the finite element model includes the GMX10-GMX14 steelconcrete composite cable tower segments and the GMX9 concrete tower column segment. All the nodes of the bottom edge in the GMX9 segment are consolidated in this model.

\section{Transmission of the Cable Force among Members of the Multisegmented Anchorage Structure}

3.1. Transmission of the Horizontal Component of Cable Force to Each Segment. To describe the calculation results conveniently, the cable force is decomposed into horizontal and vertical component forces. The value of the horizontal force borne by each component of the cable tower anchorage structure is shown in Figure 4. Considering the mutual restraint between the upper and lower segments, the horizontal force is transferred between the adjacent segments. The horizontal force of each segment does not correspond to the horizontal component of the cable force, and a segment with a higher horizontal component is also subjected to a higher horizontal force. The horizontal force of each tower segment is shown in Figure 5.

The horizontal component of the cable force is borne by the side plate of the steel anchor box, the diaphragm, and the side wall of the concrete tower column. The values for the horizontal force and ratio (the ratio of the force on each 


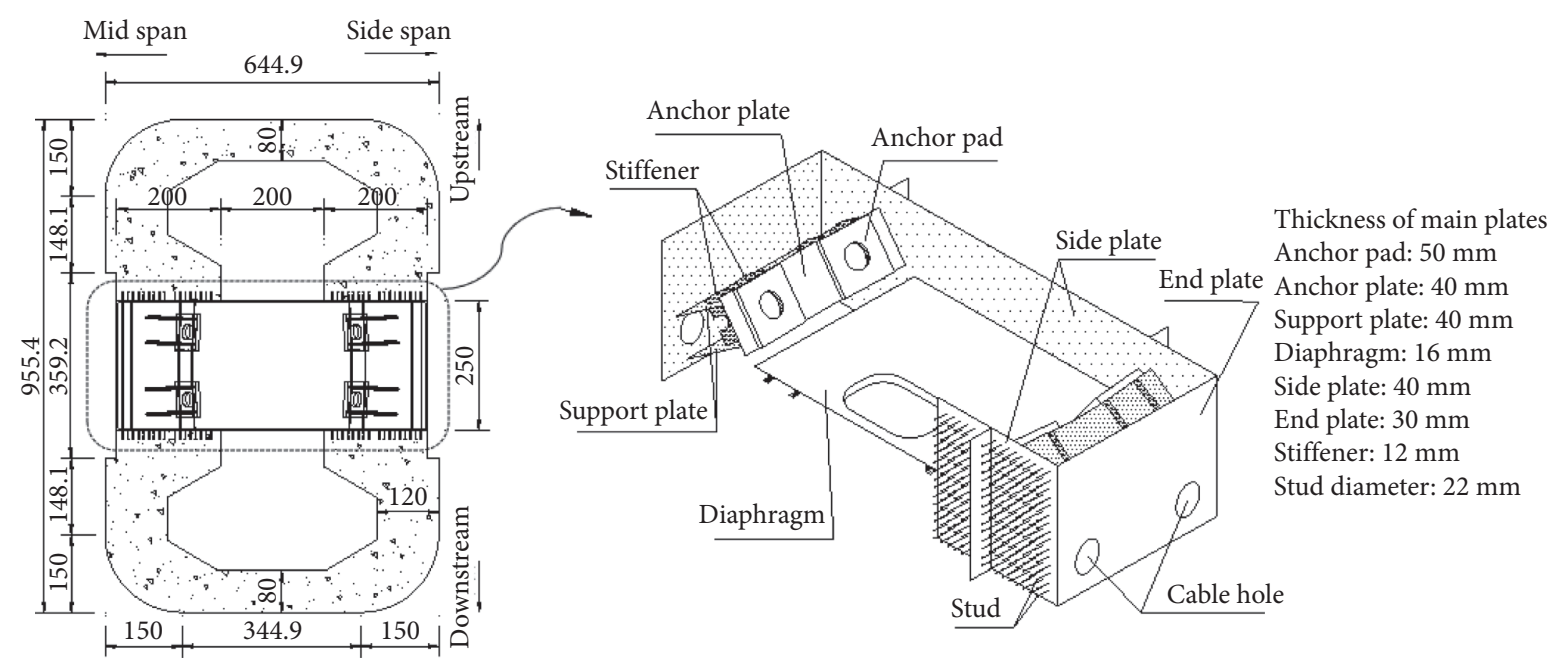

Figure 1: Tower anchor structure with an exposed steel anchor box (mm).
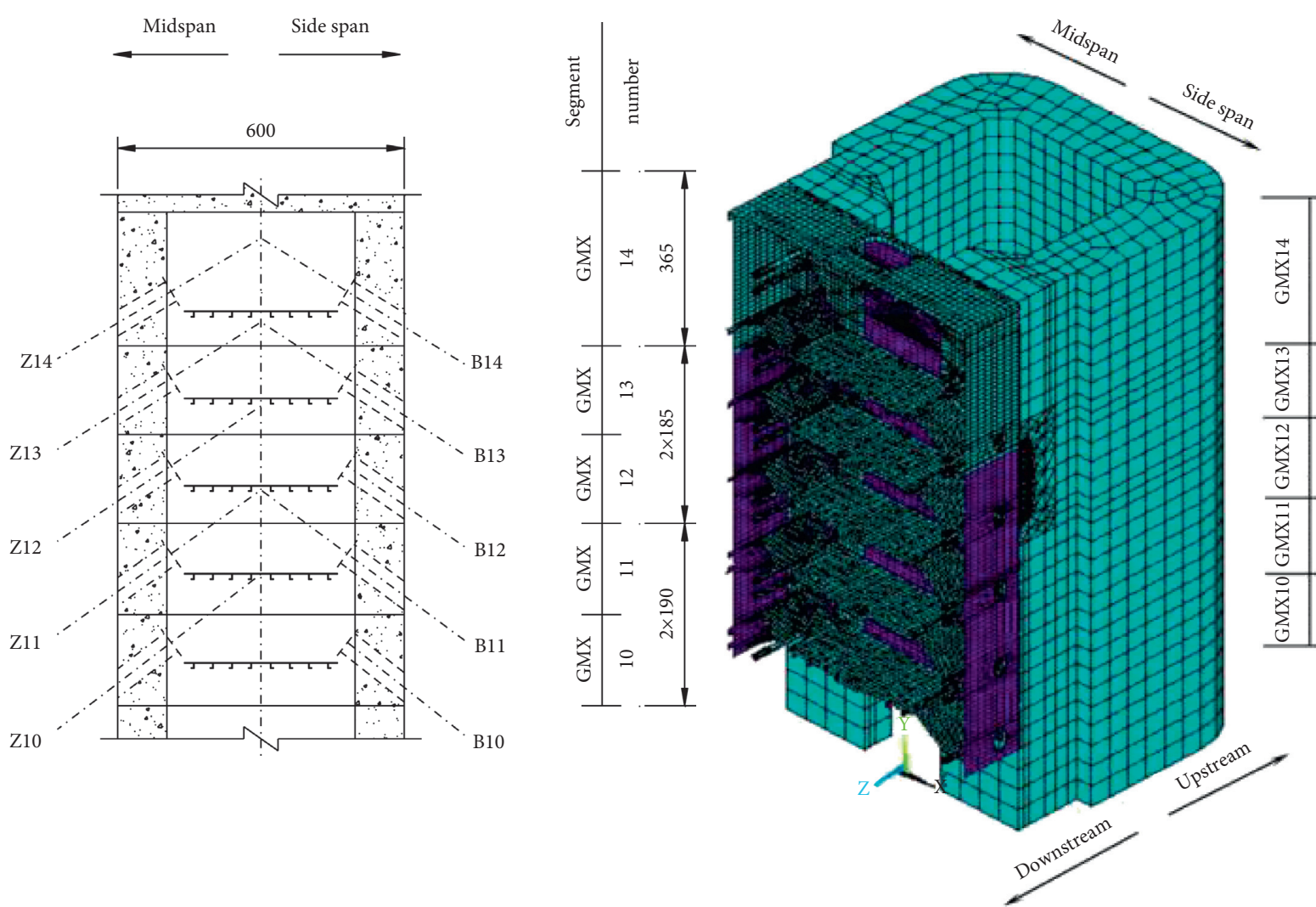

(a)

(b)

FIGURE 2: Finite element model of the anchorage structure. (a) Elevation of the anchorage structure of top 5 segments of the tower column. (b) Finite element model.

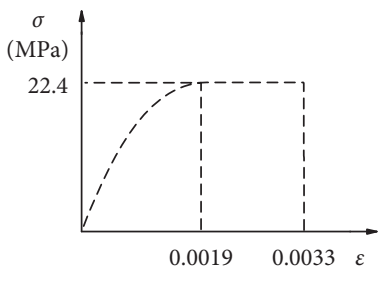

(a)

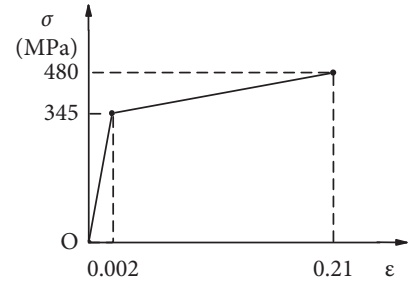

(b)

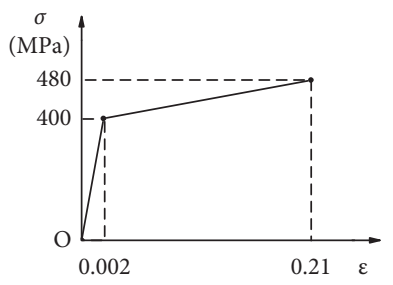

(c)

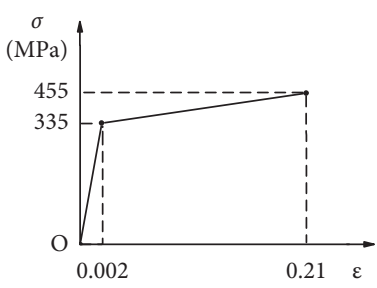

(d)

Figure 3: Constitutive relationship curves. (a) Concrete. (b) Steel plate. (c) Stud. (d) Steel bar. 
TABle 1: Cable forces of cable tower segments under dead load condition $(\mathrm{kN})$.

\begin{tabular}{|c|c|c|c|c|c|}
\hline Segment number of the cable tower & GMX10 & GMX11 & GMX12 & GMX13 & GMX14 \\
\hline Cable force & $2492 / 2339$ & $2730 / 2718$ & $2714 / 3026$ & $2963 / 3244$ & $1652 / 2392$ \\
\hline Horizontal component cable force & $1507 / 1442$ & $1574 / 1604$ & $1495 / 1708$ & $1565 / 1755$ & $839 / 1246$ \\
\hline Vertical component cable force & $1984 / 1842$ & $2231 / 2194$ & $2265 / 2499$ & $2516 / 2727$ & $1423 / 2042$ \\
\hline
\end{tabular}

Note. The number before the " $"$ " is the cable force of a single stay cable at the midspan side, and the number after the " $/$ " is the cable force of a single stay cable at the side span.

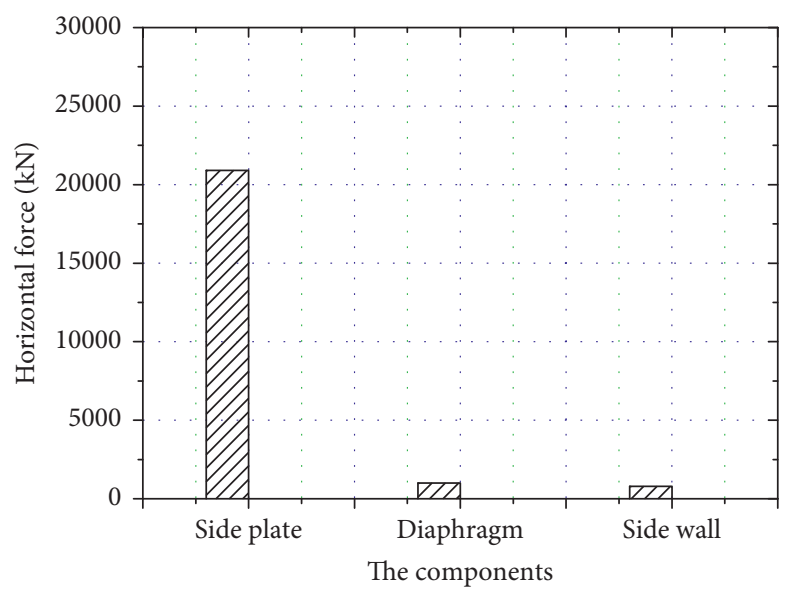

Figure 4: Horizontal force borne by each component.

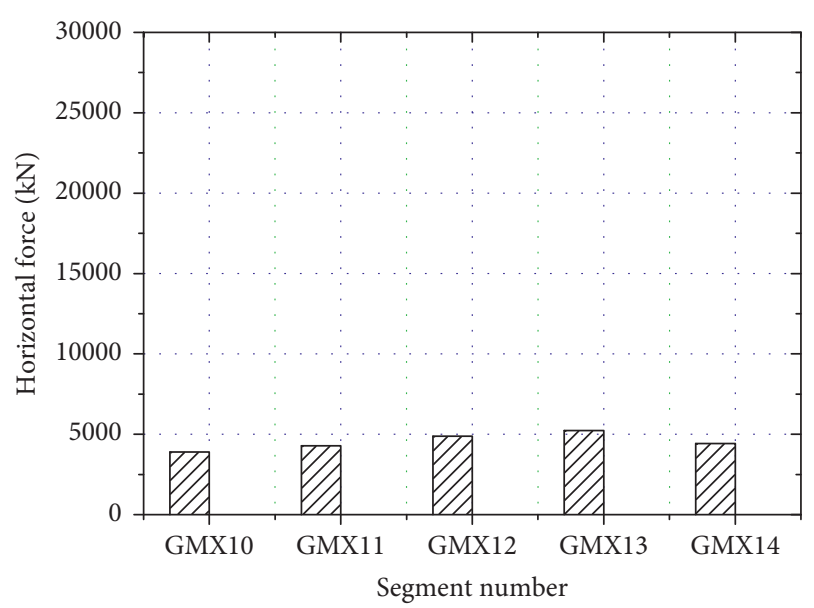

FIgURE 5: Horizontal force borne by each segment.

member to the sum of the horizontal components of the cable force on five segments) borne by the aforementioned components are shown in Figures 6-8. The results indicate that the horizontal component of the cable force borne by the side plate and diaphragm is high in the middle section and low at the two ends. The three middle segments (GMX11-13) are subjected to approximately $65 \%$ of the total balanced horizontal component of the cable force of the five segments. Although it is possible to transfer the cable force between the upper and lower segments, segments with higher horizontal components are also subjected to a higher cable force. For example, segment GMX13 is subjected to the highest horizontal force. The top segment (GMX14) of the tower side wall is constrained by the tower cap, and thus, an increase in the horizontal force on the side wall reduces the horizontal force on the lower segment (GMX10).

According to the foregoing analysis, the load-transferring mechanism of the horizontal component force for the multisegment tower anchorage structure with an exposed steel anchor box is as follows. The cable force is transferred from the anchor area to the side plate of the steel anchor box, and the side plate is elongated by the horizontal component force. Furthermore, the diaphragm welded to the side plate is stretched. Additionally, the concrete tower end wall is connected to the side plate of the steel anchor box via the stud group of the shear connector, and the deformation of the end wall leads to the tensile deformation of the concrete tower side wall. Therefore, the horizontal component of the cable force is jointly supported by the side plate and diaphragm of the steel anchor box and the side wall of the concrete tower, with the vast majority of the force supported by the steel anchor box.

\subsection{Transmission of the Vertical Component of Cable Force in} Each Segment. The vertical force transmitted by each anchorage segment is shown in Figure 9. The results indicate that a greater amount of the vertical force is transferred to the lower cable tower sections because of the accumulation of the vertical force.

The vertical force transmitted by the steel anchor box and tower wall of each section and the proportion of this vertical force with respect to the total vertical force transmitted by this segment are shown in Figures 10 and 11, respectively. Based on the calculation results, the vertical force transmitted by the concrete tower wall of each section 


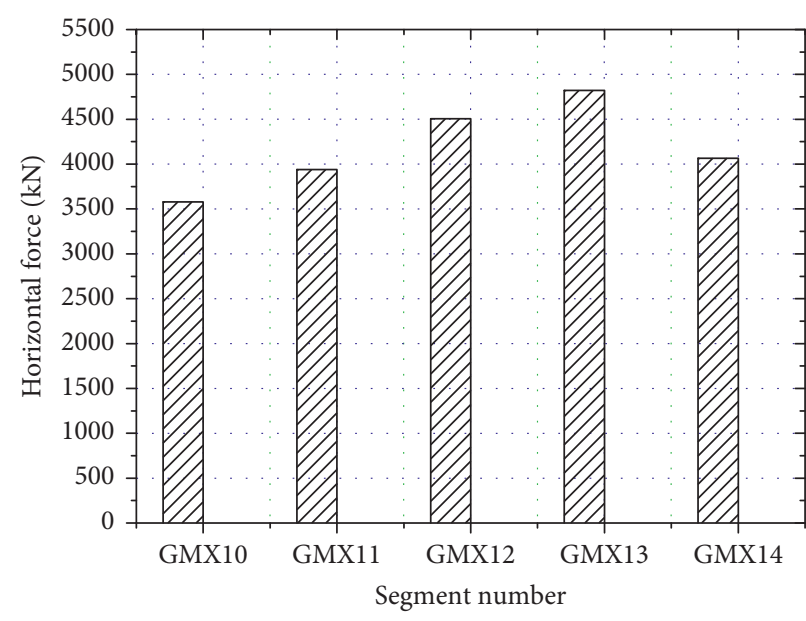

(a)

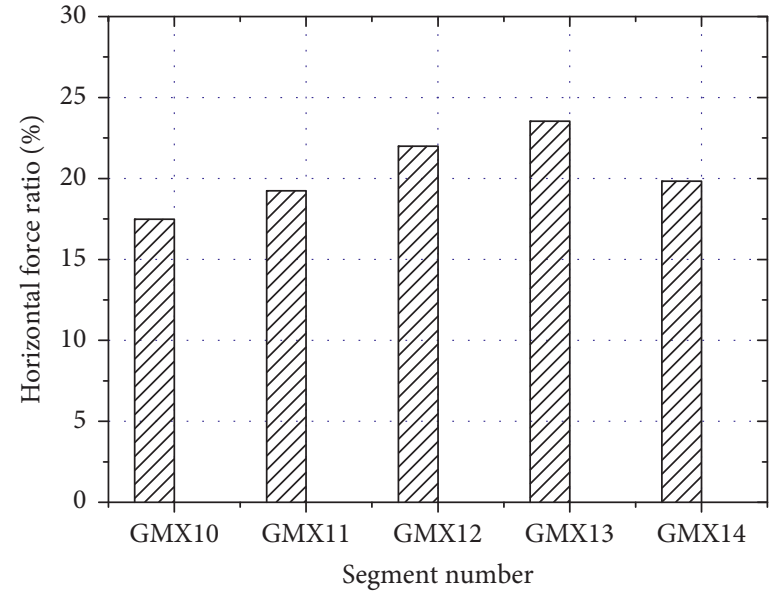

(b)

Figure 6: Horizontal force and its ratio borne by the side plate of each segment. (a) Horizontal force. (b) Horizontal force ratio.

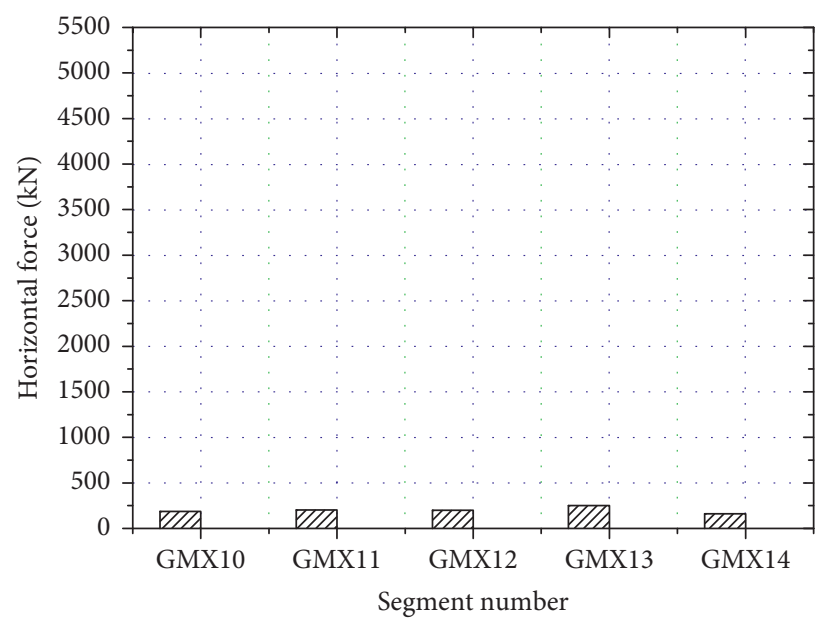

(a)

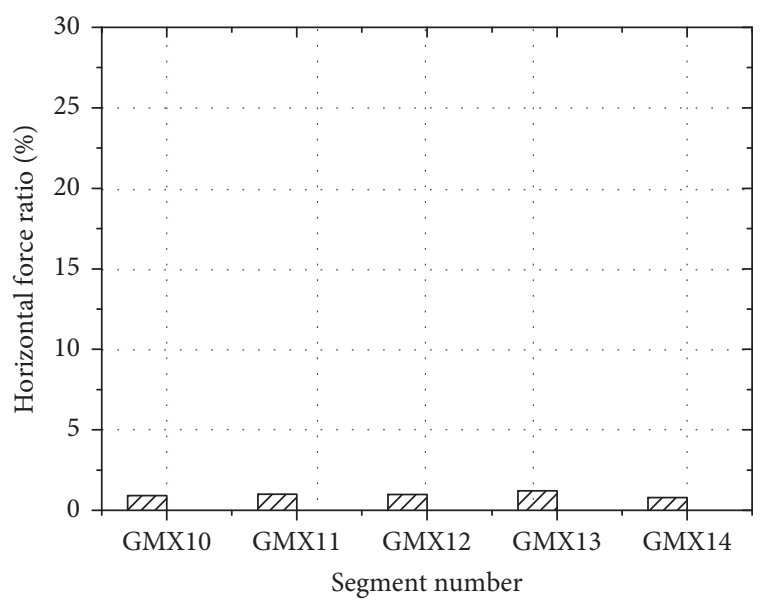

(b)

Figure 7: Horizontal force and its proportion borne by the diaphragm of each segment. (a) Horizontal force. (b) Horizontal force ratio.

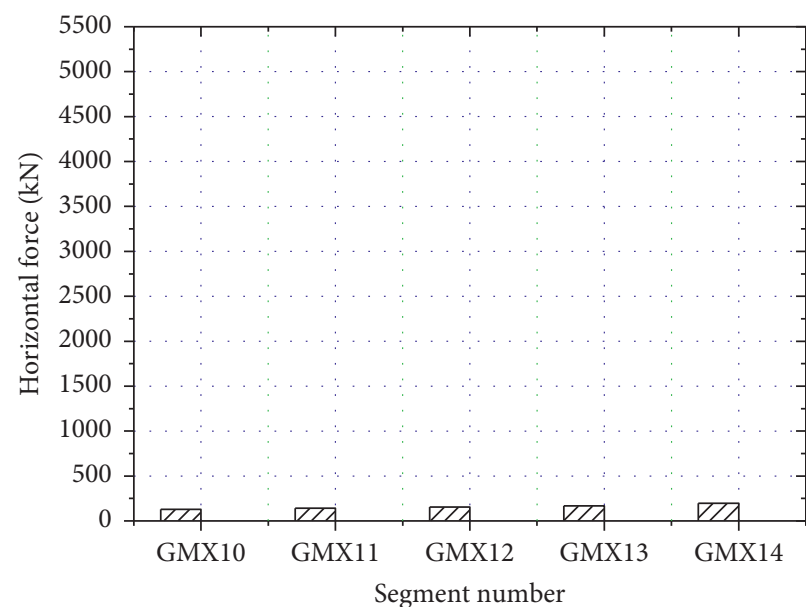

(a)

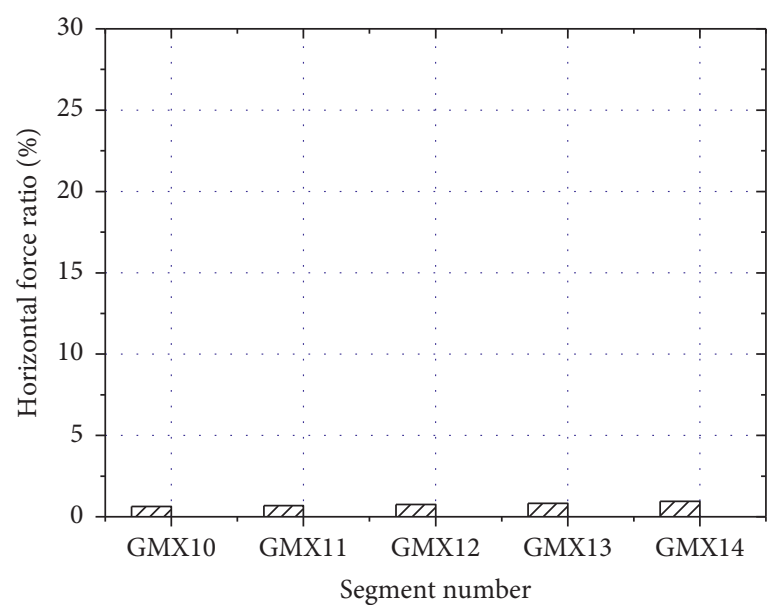

(b)

FIGURE 8: Horizontal force and its proportion borne by the side wall of each segment. (a) Horizontal force. (b) Horizontal force ratio. 


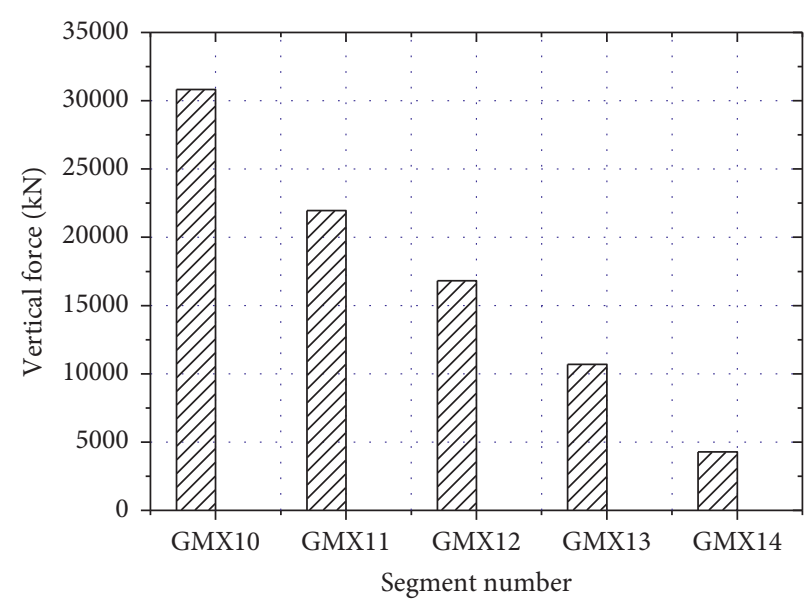

FIGURE 9: Vertical force transferred by each anchor segment.

exceeds that transmitted by the steel anchor box and accounted for more than $85 \%$ of the total vertical force of each section. The vertical component of the cable force is transferred downward segment by segment, and hence, a higher vertical force is transferred to the lower segments. The bottom part of the concrete tower column is compressed under the large vertical force. Because of the collaborative deformation of the stud group, the ratio of the vertical force $(\mathrm{a} / \mathrm{b})$ is higher for lower steel anchor box segments, and the ratio of the vertical force transmitted by the lower concrete tower wall decreases accordingly.

According to the foregoing analysis, the load-transferring mechanism of the vertical component force for the multisegment tower anchorage structure with an exposed steel anchor box is as follows. When the anchorage structure with the exposed steel anchor box is subjected to the cable force, a portion of the vertical component of the cable force is directly transferred downward by the connecting steel anchor box. The other portion is transferred to the concrete tower wall through the shear connector studs and then transferred segment by segment. Hence, the vertical component of the cable force is transmitted downward by the steel anchor box and the tower wall.

\section{Stress in Components and Shear Force in the Stud Group of Anchorage Structure}

4.1. Stress Distribution of Each Component. The distributions of the von Mises stresses on the side plate and diaphragm of the steel anchor box are shown in Figures 12 and 13, respectively. The two aforementioned components are subjected to most of the horizontal component of the cable force, and their forces are mainly tensile. Regions with higher tensile stress levels are observed in the GMX12 and GMX13 segments, and the horizontal component of the cable force is higher. The peak stress of the side plate is 135.3 MPa, which is observed at the joint of the GMX13 section and the anchor plate. The peak stress of the diaphragm is $56.6 \mathrm{MPa}$, which is observed at the junction with the side plate in the GMX12 segment.
The distribution of von Mises stress on the end plate of the steel anchor box is shown in Figure 14. The end plate is connected to the side plate to form a frame. The end plate is also directly connected to the supporting plate. The end plate is subjected to the cable force from the supporting plate and exhibited an outward expansion deformation. The von Mises stress distribution of the end plate mainly corresponds to tensile stress. The von Mises stress level of the end plate gradually increases for the lower segments. The total stress level of the end plate is low. In the dead load state of the bridge, the peak stress is $100.94 \mathrm{MPa}$, which is observed in the lower edge corner of the side span.

The distributions of the principal compressive stress and principal tensile stress on the concrete tower wall of the anchored structure are shown in Figures 15 and 16, respectively. The results indicate that the concrete tower is mainly compressed and that the high-stress area is mainly distributed in the concrete end wall corresponding to the lower edge of the bearing plate of the steel anchor box. In the steel-concrete joint, given the shear deformation of the stud group, the stress of the concrete connected to the stud group is significantly disturbed, and stress concentration is observed.

4.2. Shear Distribution of the Stud Group. The stud group shear connector of the anchor box anchorage structure is subjected to horizontal and vertical force components of the cable force; that is, the connector is under a slant force state. In order to describe the calculation results conveniently, the shear force of the studs is decomposed into the vertical component of the shear force (vertical shear force) and horizontal component of the shear force (horizontal shear force).The numbering convention of the stud group is shown in Figure 17. Under the cable force of the dead load condition, the distribution of the high vertical shear force position (i.e., the $17^{\text {th }}$ row of the side span in the steel anchor box) of the stud group along the height direction is shown in Figure 18. The vertical shear distribution of the stud group in the GMX13 segment is shown in Figure 19. It is observed that, under the slant force, the area with the higher shear 


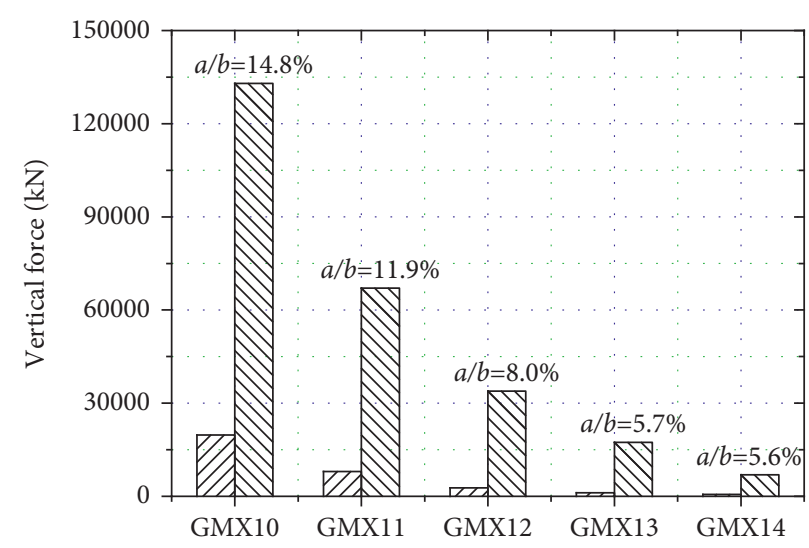

[य] $a$-Vertical force transmitted by steel anchor box of each section

$b$-Total vertical force transmitted by the segment

Figure 10: Vertical force transferred by the steel anchor box.

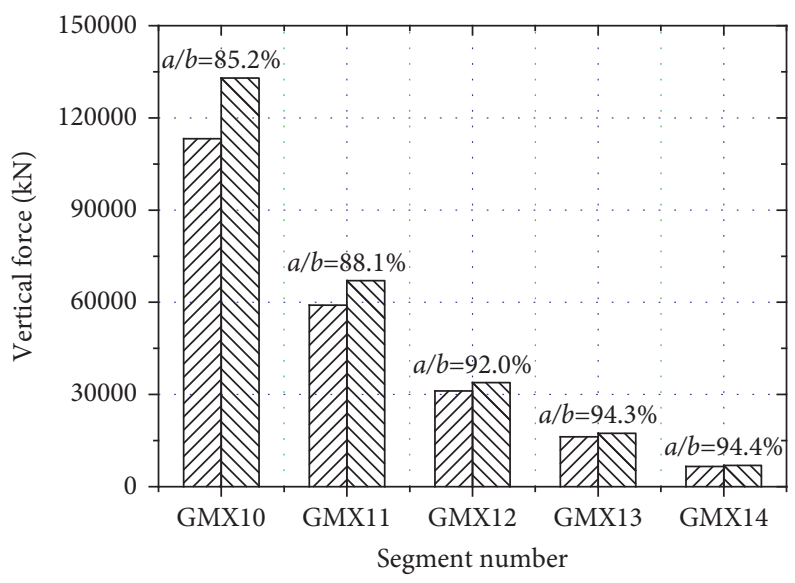

ZII $a$-Vertical force transmitted by steel anchor box of each section

$b$-Total vertical force transmitted by the segment

FIgURE 11: Vertical force transferred by the tower wall.

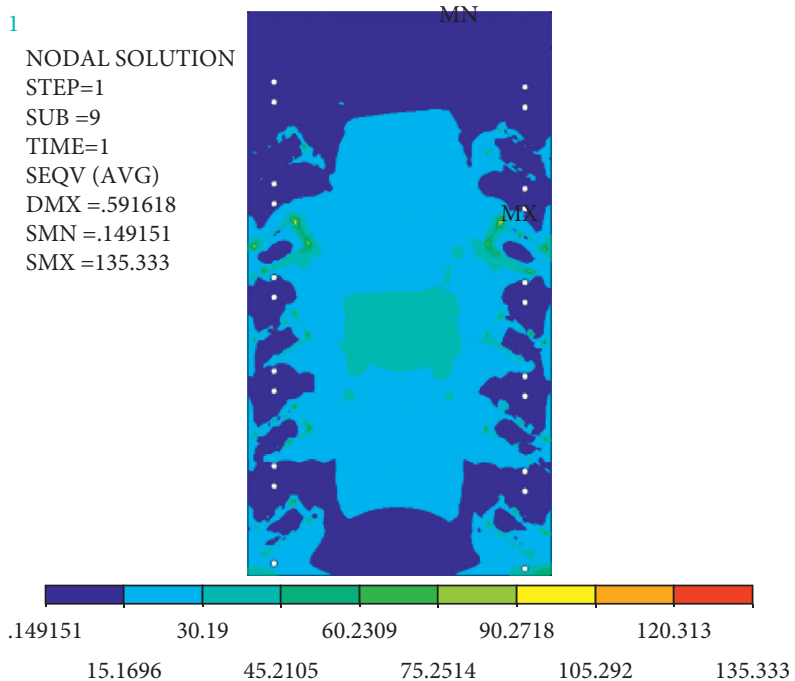

Figure 12: von Mises stress distribution of the side plate (MPa). 


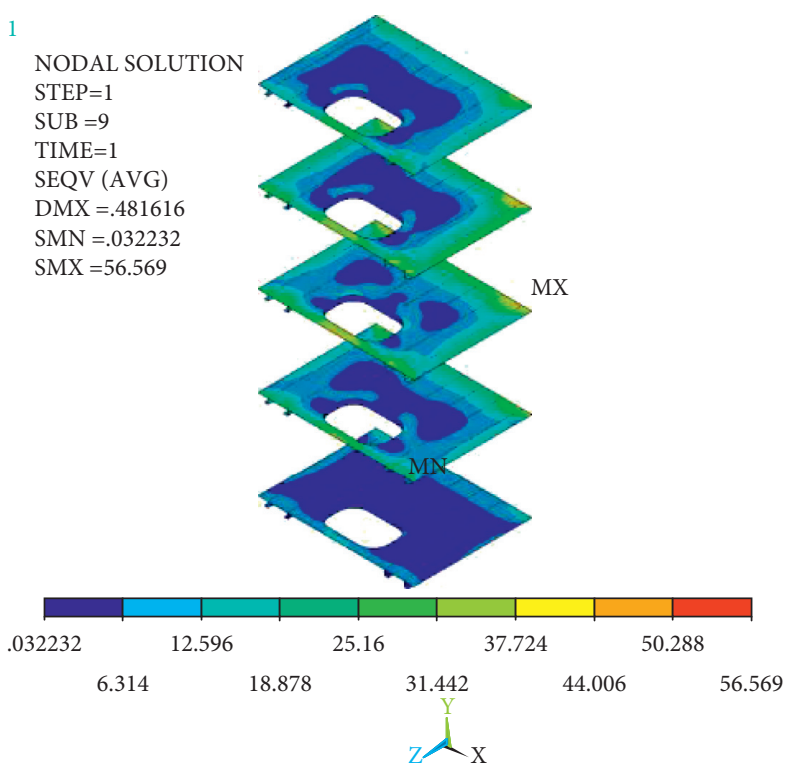

FIGURE 13: von Mises stress distribution of the diaphragm (MPa).

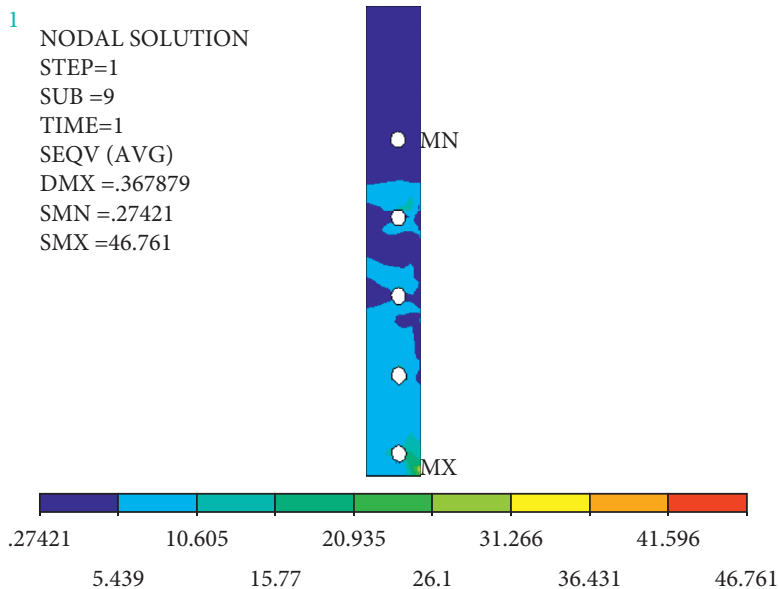

(a)

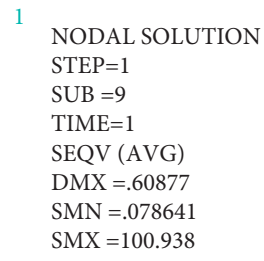

SMX $=100.938$

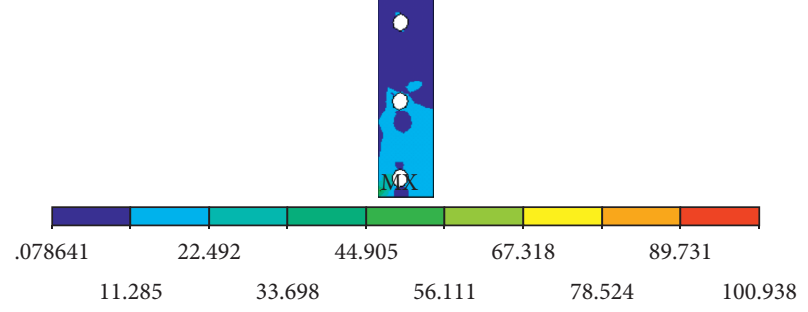

(b)

FIgURE 14: von Mises stress distribution of the end plate (MPa). (a) Midspan. (b) Side span.

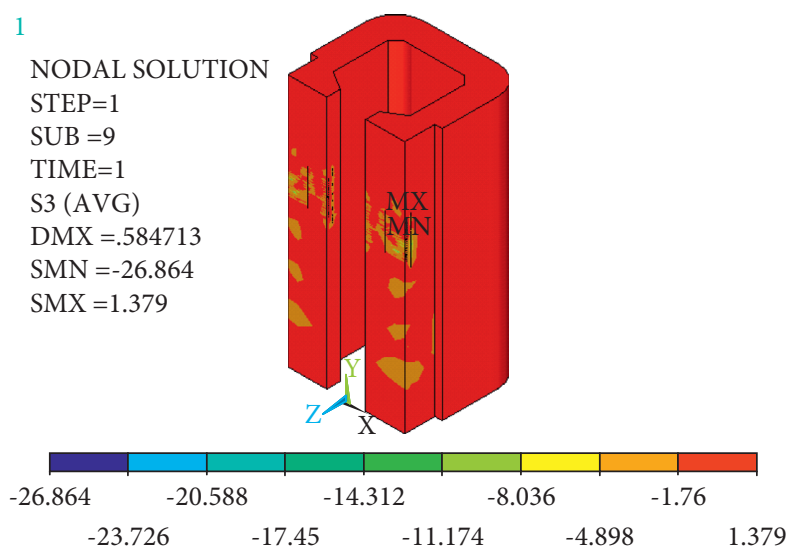

FIGURE 15: Principal compressive stress distribution of the concrete cable tower (MPa). 


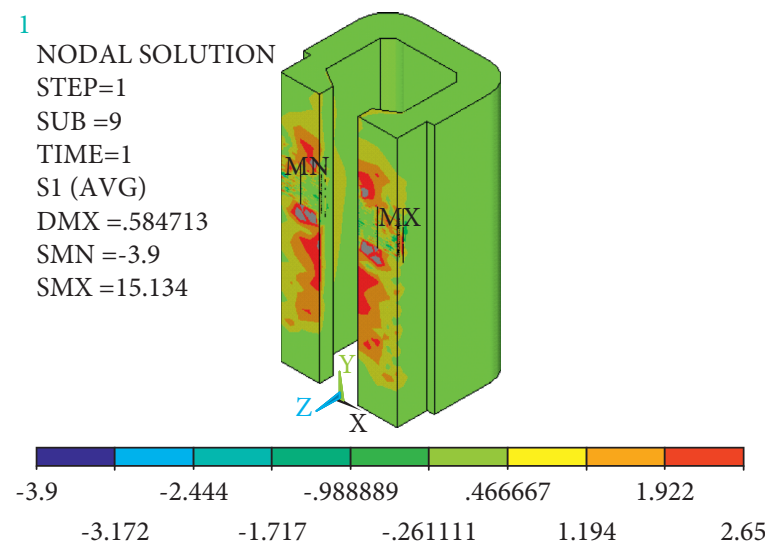

FIgURE 16: Principal tensile stress distributions of the concrete cable tower ( $\mathrm{MPa})$.

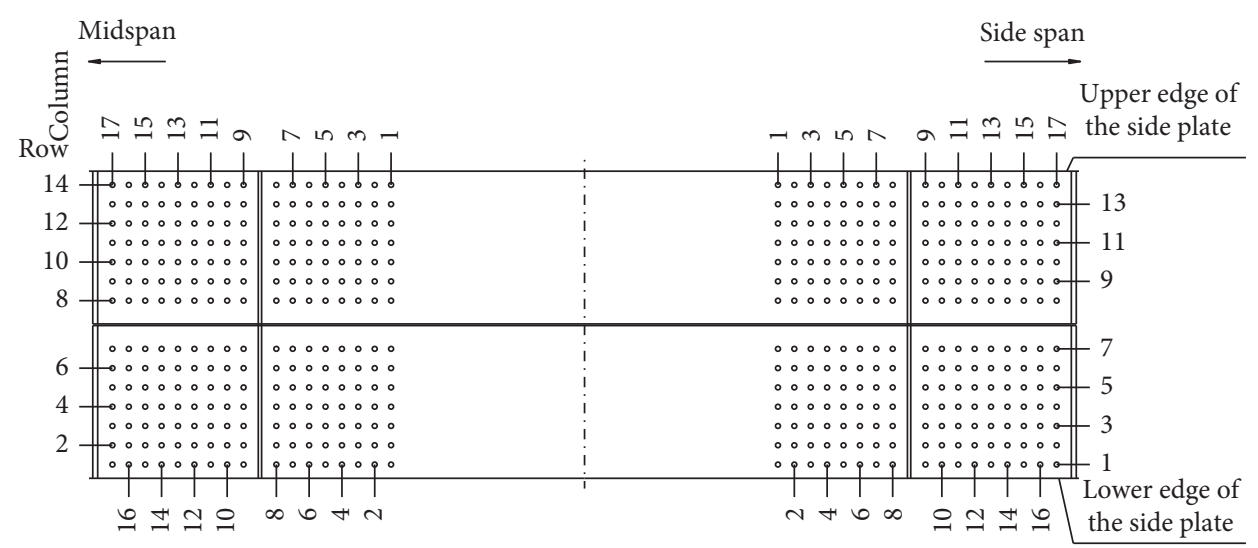

Figure 17: Stud group numbers.

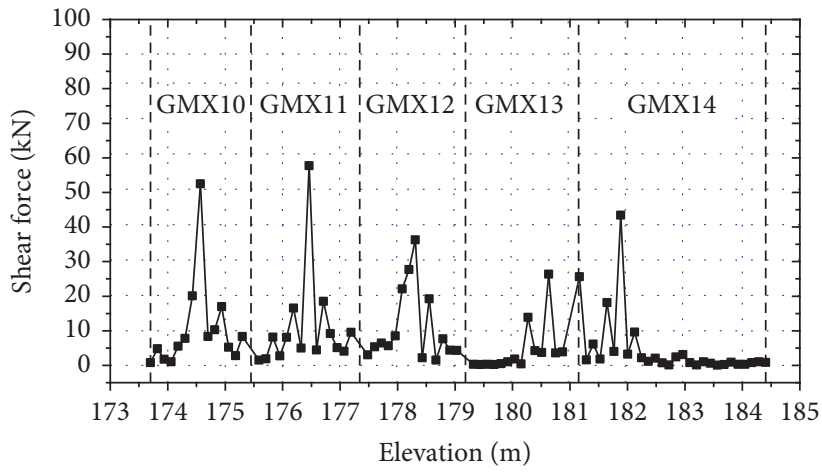

(a)

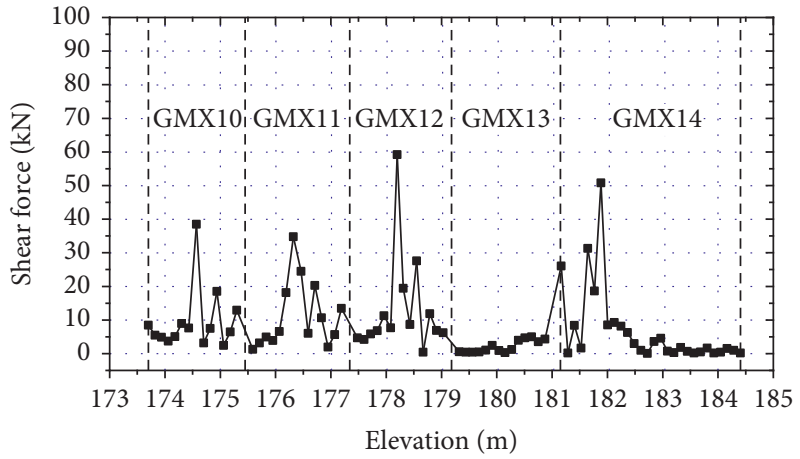

(b)

Figure 18: Vertical shear force distribution of studs along height of the cable tower. (a) Shear force of $17^{\text {th }}$-row studs of midspan. (b) Shear force of $17^{\text {th }}$-row studs of side span.

force appeared on both sides of the stud group, and the distribution of the vertical shear force is "saddle-shaped" along the height. However, the shape is not evident. This distribution is different from that of the stud group under vertical or horizontal force only.

The horizontal shear force distribution of the stud group is shown in Figure 19. Given the deformation of the side plate, the horizontal shear direction of the stud group is inconsistent, and the horizontal shear exists in two directions: (i) toward the mid span (denoted by "+" values in the Figure 20) and (ii) toward the side span (denoted by "-" values in Figure 20). The horizontal shear force of the stud group does not exhibit a significant "saddle-shaped" distribution either. The horizontal shear force direction of the 


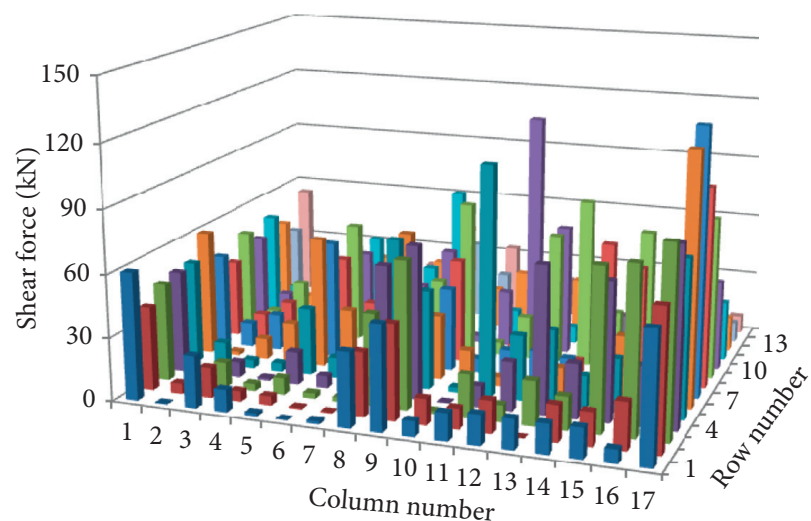

(a)

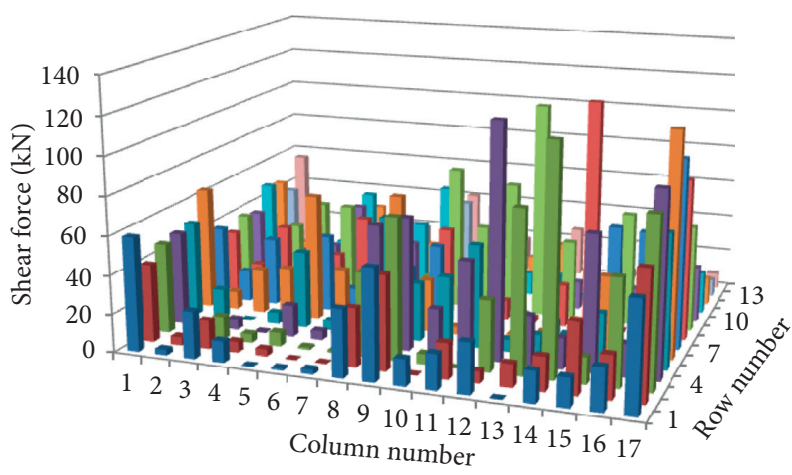

(b)

FIgURE 19: Vertical shear distribution of the stud group in GMX13 segment. (a) Midspan. (b) Side span.

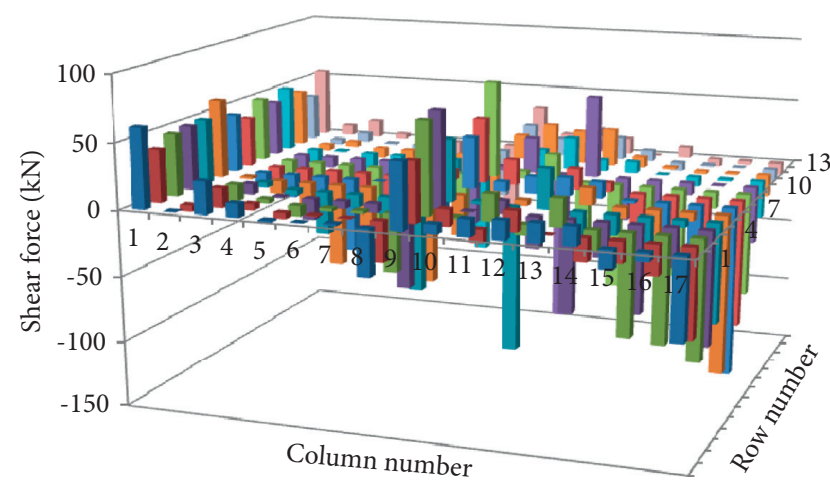

(a)

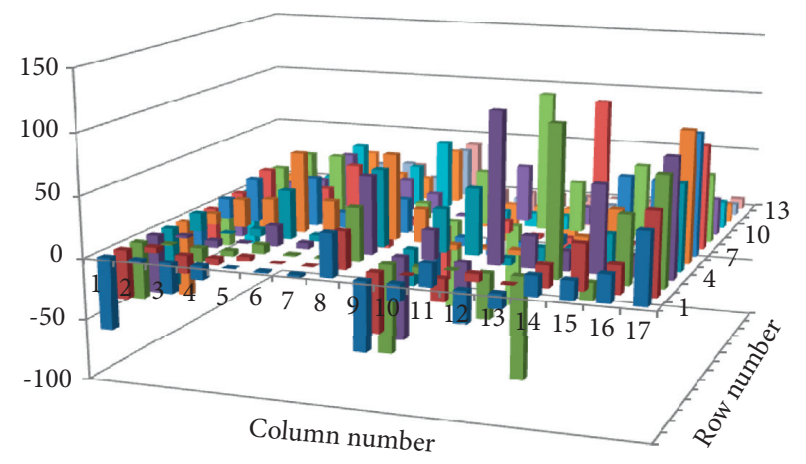

(b)

FIgURE 20: Horizontal shear distribution of the stud group in GMX13 segment. (a) Midspan. (b) Side span.

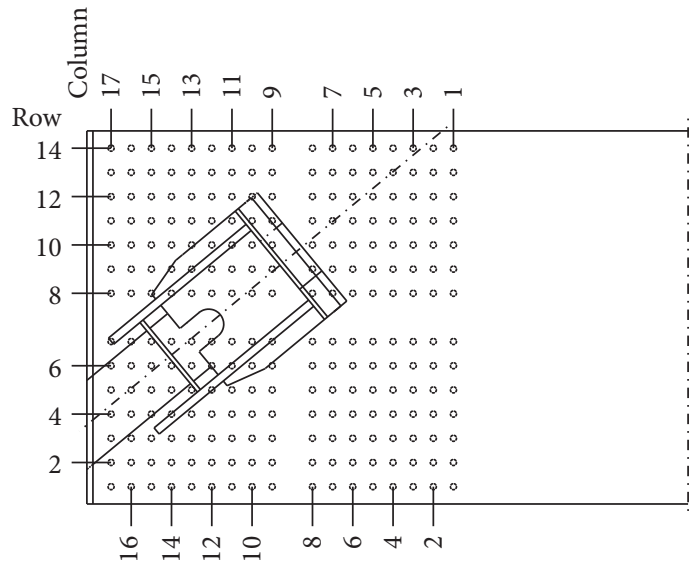

(a)

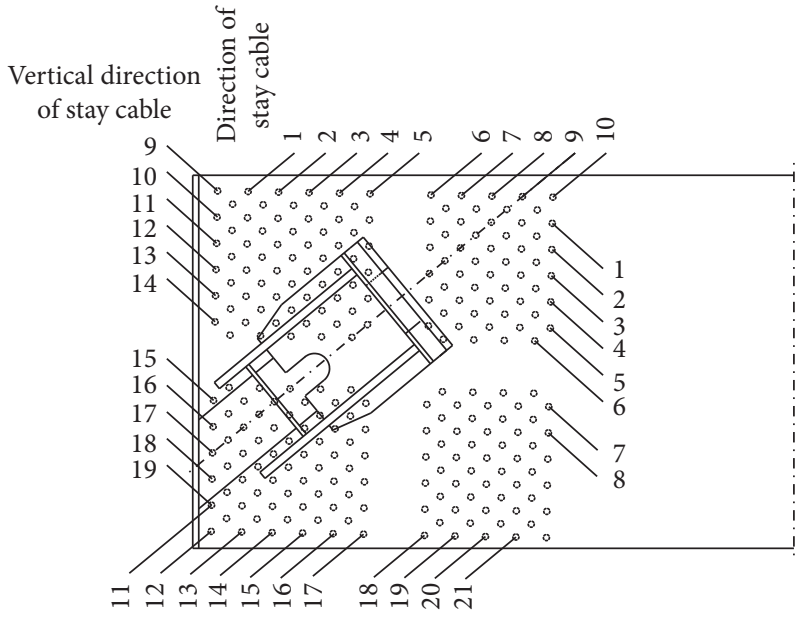

(b)

FIgURE 21: Optimal arrangement for the stud group. (a) Original arrangement. (b) Optimal arrangement.

stud group on the mid-span side is mainly toward the mid span, while the shear force direction of the side-span side is mainly toward the side span. The horizontal shear force distribution of the stud group is uneven, and the studs on the two sides of the stud group ( $1^{\text {st }}$ and $17^{\text {th }}$ columns), near the shear plate ( $8^{\text {th }}$ and $9^{\text {th }}$ columns), and at the connection 
between the diaphragm and side plate ( $6^{\text {th }}$ and $7^{\text {th }}$ rows) sustain high horizontal shear forces.

4.3. Design Suggestions. The stud group shear connector of the anchor box anchorage structure is in a complex stress state and is subjected to the slant force. Furthermore, the shear force distribution in the stud group does not exhibit evident regularity, which is unfavorable for the design. A stress analysis of the anchorage structure with the built-in steel anchor box has been performed. The results indicate that the stud group is under a vertical force and that its stress distribution presents a regular pattern with a "saddle-shaped" $[20,21]$. Hence, the arrangement of the stud group of the exposed steel anchor box is investigated considering the angle of the stay cable, that is, changing the row and column layout in the direction of the stay cable (Figure 21). In the optimal arrangement for the structure, the shear force of the stud group is transmitted along the row direction, which will clarify the mechanical performance of the stud group.

\section{Conclusions}

A finite element analysis was performed to examine the force transmission of a multisegment tower anchorage structure with an exposed steel anchor box. The stress distribution of each member and the shear distribution of the stud group were also analyzed. The main results of the study are as follows:

(1) The horizontal component of the cable force of the anchorage structure is borne by the concrete sidewall, side plate, and transverse diaphragm of the steel anchor box. The horizontal component of the cable force borne by the side plate and diaphragm is high in the middle section and low at the two ends. Furthermore, among the five segments, the three middle segments withstand approximately $65 \%$ of the total balanced horizontal component of the cable force.

(2) A portion of the vertical component of the cable force is transmitted downward by the connected steel anchor box, and the other portion is transmitted to the concrete tower wall segment by the segment through the stud group shear connector. The vertical force transmitted by the concrete tower wall of each segment exceeds that transmitted by the steel anchor box and accounted for more than $85 \%$ of the total vertical force of each section.

(3) The side plates, diaphragm, and end plates of the steel anchor box are mainly in a tensile state. The concrete tower column is mainly compressed, and the highstress regions are mainly distributed in the concrete end wall corresponding to the edge of bearing plate. Stress concentration is observed at the corresponding positions of the studs.

(4) The stud group of the anchorage structure is under a slant force, and the shear distribution is uneven. The vertical and horizontal shear force distributions of the stud group do not exhibit a significant "saddleshaped" distribution. Finally, an optimal arrangement method for the stud group was proposed to optimize its mechanical performance.

\section{Data Availability}

The data used to support the findings of this study are included within the article.

\section{Conflicts of Interest}

The authors declare that they have no conflicts of interest.

\section{Acknowledgments}

This study was funded by the Opening Foundation of Henan Key Laboratory of Grain and Oil Storage Facility \& Safety (2021KF-B05) and Henan University of Technology High Level Talent Research Fund Project (2016BS002).

\section{References}

[1] M. Virlogeux, "New trends in prestressed concrete bridges," Structural Concrete, vol. 3, no. 2, pp. 67-97, 2002.

[2] Q. Wang, "Parametric design and application of steel anchor box for main girder of long span cable-stayed bridge," IOP Conference Series: Materials Science and Engineering, vol. 392, no. 6, p. 62007, 2018.

[3] W. Zhao, Z. Wu, L. Claude, and L. Frédéric, "Research on steel anchor box design of Morocco Mohammed VI cable-stayed Bridge," Journal of Nanchang Institute of Technology, vol. 39, no. 3, pp. 23-27, 2020.

[4] K. Liu, W. Xing, Y. Zeng, and W. Yin, "Techniques for in stallation, measuring and positioning contror of steel anchor boxes in pylons of jialingjiang river bridge in hongyan village," World Bridge, vol. 48, no. 4, pp. 36-41, 2018.

[5] J. Sun and L. Chen, "Study on performance of 1 \# bridge engineering cable pylon anchorage zone in caofeidian industrial area," Urban Roads Bridges \& Flood Control, no. 4, pp. 194-197, 2011.

[6] H. Xu, C. He, Y. Chen, C. Huang, and X. Wang, "Design and structural analysis of cable tower anchorage structure with steel anchor box of cable stayed bridge," Journal of China and Foreign Highway, vol. 35, no. 5, pp. 190-193, 2015.

[7] M. Virlogeux, "The n bridge, France: a new record for cablestayed bridges," Structural Engineering International, vol. 4, no. 4, pp. 208-213, 1994.

[8] J. Combault, A. Pecker, J.-P. Teyssandier, and J.-M. Tourtois, "Rion-antirion bridge, Greece - concept, design, and construction," Structural Engineering International, vol. 15, no. 1, p. 22, 2005.

[9] W. Lin and R. Chen, "Construction techniques for steel anchor housing of north navigable bridge of Hangzhou Bay bridge," Bridge Construction, no. 1, pp. 46-49, 2007.

[10] G. Morgenthal, R. Sham, and B. West, "Engineering the tower and main span construction of stonecutters bridge," Journal of Bridge Engineering, vol. 15, no. 2, pp. 144-152, 2010.

[11] M. Hu, B. Huang, J. Yu, and S. Tang, "Key techniques for design of edong changjiang river highway bridge," Bridge Construction, no. 5, pp. 64-68, 2011.

[12] H. Xu, Y. Liu, Y. Li, and S. Zheng, "Experimental study on stress mechanism of exposed steel anchor box cable-tower 
achor," Journal of Tongji University, vol. 42, no. 5, pp. 672676, 2014.

[13] M. Zeng, Q. Su, C. Shao, and C. Wu, "Test study on the cablepylon anchorage zone of highway and light railway long-span cable-stayed bridge," China Railway Science, vol. 29, no. 4, pp. 53-57, 2008.

[14] Q. Zhang and M. Li, "Segmental model test study of steel and concrete composite anchor zone on pylon of cable-stayed bridge," Bridge Construction, no. 3, pp. 16-19, 2006.

[15] X. Li, L. Zhao, L. Xiao, and D. Liu, "Mechanical behaviour of the anchor of steel-concrete hybrid pylon of cable-stayed bridge," Proceedings of the $23^{\text {rd }}$ National Conference on Structural Engineering, vol. 1, pp. 399-406, 2014.

[16] X. Yu and Q. Zhang, "Study on segmental model test of steelconcrete composite pylon anchorage structure," Railway Engineering, no. 8, pp. 16-18, 2008.

[17] L. Xiao, L. Liu, X. Wei, and D. Liu, "Mechanical behavior and structural optimization of steel-concrete composite cablepylon anchor," Journal of Southwest Jiaotong University, vol. 54, no. 5, pp. 923-930, 2019.

[18] M. Zhang, S. Tang, and M. Liu, "Parametric sensitivity analysis for composite cable-pylon anchor structure with PBL connection," Bridge Construction, no. 6, pp. 72-77, 2019.

[19] W. Wu, M. Liu, and Y. Liu, "Model test of PBL connection part in composite cable-pylon anchorage zone of cable-stayed bridge," World Bridges, no. 1, pp. 32-37, 2019.

[20] W. Lu, Y. Zhao, M. Zhao, and D. Tan, "Effects of connections of exposed steel anchor boxes on the mechanical behaviour of pylon anchorage system," Science and Technology Review, vol. 34, no. 2, pp. 265-270, 2016.

[21] W. Lu and M. Zhao, "Transfer mechanism of multiple segmental pylon anchorage structure with built-in steel anchor box," Highways, no. 11, pp. 159-166, 2020.

[22] L. Nie, X. Wang, and J. Zhou, "Analysis of stress at anchoring zone of concrete tower considering temperature effet," Highways, no. 4, pp. 110-114, 2019.

[23] Y. Liu, C. Chen, and S. Zheng, "Analysis of force mechanism of pylon anchorage structure of fixed- end steel anchor box type," Bridge Construction, vol. 45, no. 1, pp. 33-38, 2015.

[24] Q. Wu, J. Dai, M. Wei, and W. Pan, "Determination of test parameters of full-scale model test of pylon anchorage zone segment for Wujiang river bridge," Journal of Civil Engineering and Management, vol. 34, no. 4, pp. 7-13, 2017.

[25] J. Liang, "Study on mechanical properties of steel anchor box tower anchorage zone of railway cable-stayed bridge," Railway Survey and Design, no. 3, pp. 35-39, 2020.

[26] X. Zhang and Y. Liu, Cable-Tower Composite Anchorage, China Communications Press, Beijing, China, 2010.

[27] Gb 50010-2019, Code for Design of Concrete Structures, China Building Industry Press, Beijing, China, 2019. 